University of Nebraska - Lincoln

DigitalCommons@University of Nebraska - Lincoln

Faculty Publications: Department of Teaching, Department of Teaching, Learning and Teacher Learning and Teacher Education

Education

2003

\title{
Preservice Elementary School Teachers' Understandings of Theory Based Science Education
}

\author{
Edmund A. Marek \\ University of Oklahoma \\ Timothy A. Laubach \\ University of Oklahoma \\ Jon Pedersen \\ University of Oklahoma, jpedersen2@unl.edu
}

Follow this and additional works at: https://digitalcommons.unl.edu/teachlearnfacpub

Part of the Teacher Education and Professional Development Commons

Marek, Edmund A.; Laubach, Timothy A.; and Pedersen, Jon, "Preservice Elementary School Teachers' Understandings of Theory Based Science Education" (2003). Faculty Publications: Department of Teaching, Learning and Teacher Education. 93.

https://digitalcommons.unl.edu/teachlearnfacpub/93

This Article is brought to you for free and open access by the Department of Teaching, Learning and Teacher Education at DigitalCommons@University of Nebraska - Lincoln. It has been accepted for inclusion in Faculty Publications: Department of Teaching, Learning and Teacher Education by an authorized administrator of DigitalCommons@University of Nebraska - Lincoln. 


\title{
Preservice Elementary School Teachers' Understandings of Theory Based Science Education
}

\author{
Edmund A. Marek, Timothy A. Laubach, and Jon Pedersen \\ Science Education Center, University of Oklahoma, \\ Norman, Oklahoma 73019, U.S.A.
}

As we begin the new millennium, leaders in science education continue to urge elementary, middle, and high school science teachers to implement inquiry practices designed to develop students' scientific process skills and understandings of scientific concepts. Learning science through inquiry is supported by many educational reform documents, such as Science for All Americans (American Association for the Advancement of Science [AAAS], 1990); Benchmarks for Science Literacy (AAAS, 1993); the National Science Education Standards (National Research Council [NRC], 1996); How Students Learn: Reforming Schools Through Learner-Centered Education (American Psychological Association [APA], 1998), and How People Learn: Brain, Mind, Experience, and School (NRC, 1999). Moreover, NSTA/NCATE (1998) expects all science teacher preparation programs to prepare teachers by "facilitate[ing] an understanding of the role inquiry plays in the development of scientific knowledge" and in understanding the nature of science.

Undergirding the science education program examined in this study is a theoretical foundation based upon four cornerstones that reflect scientific inquiry. These four cornerstones are best represented by four key questions: (a) What is science; (b) What are the goals or standards for elementary school science education; (c) What theory describes how elementary school children construct knowledge; and (d) What teaching approach represents the discipline of science, achieves the goals of elementary school science education and accommodates to how children construct knowledge? The learning cycle (Barman \& Kotar, 1989; Bentley, Ebert,\& Ebert II, 2000; Lawson, Abraham, \& Renner, 1989; Marek \& Cavallo, 1997) is an inquiry based teaching approach and is the mortar that cements our theory base for science education (Renner \& Marek, 1990).

The three-phase learning cycle was derived from Piaget's model of mental functioning. The Exploration phase of the learning cycle allows learners to assimilate the essence of the science concept. In other words, the first steps toward developing concept understanding are to gather pertinent data through direct experiences and to do so until disequilibrated. The Concept Introduction phase is designed to guide learners in the interpretation of their data and experiences resulting in reequilibration and the accommodation of the science concept. The Concept Application phase of the learning cycle provides learners with opportunities to relate the newly developed science concept to everyday applications and to other concepts through a cognitive process Piaget called organization. 
The learning cycle is not a method or model of teaching. Models of teaching are sequences of conditions to increase the probability that the student will acquire a particular performance based on types of learning and subject matter (Joyce, Weil, \& Calhoun, 2000). The learning cycle, a comprehensive approach, is a specific organization of phases dominated by the integrity of the whole and the relationships of the phases to each other for experiencing science by inquiry and for organizing science curricula. The learning cycle, by design, accommodates all tools and methods of teaching (e.g. technology, questioning strategies, group work, demonstrations, laboratory investigations, field trips, lectures) as well as all models of instruction (e.g. jigsaw I, synectics, cooperative learning, direct instruction). Through its fundamental nature, the learning cycle fosters scientific inquiry by allowing students to question and formulate solvable problems; to reflect on and construct knowledge from data; to collaborate and exchange information while seeking solutions; and to develop concepts and relationships from empirical experience. It is this interface between scientific inquiry and the individual student that the learning cycle may improve the quality of education (Ammon \& Black as cited in APA, 1998).

The learning cycle continues to be an integral component of many teaching practices and research endeavors. Recent publications indicate the learning cycle is an effective teaching approach that enhances student outcomes (Barman, 1993; Blank, 2000; Cavallo \& Laubach, 2001; Dwyer \& Lopez, 2001; Gang, 1995; Jinkins, 2002; Lavoie, 1999; Marek \& Methven, 1991; Musheno \& Lawson, 1999; Norman, 1992; Norman \& Caseau, 1995; Odom \& Kelly, 2001) and teacher behaviors (Barman, 1992; Barman, 1993; Barman \& Shedd, 1992; Francis, Hill, \& Redden, 1991; Glasson \& Lalik, 1993; Jinkins, 2001; Marek, Eubanks, \& Gallaher, 1990; Marek \& Methven, 1991; Odom \& Settlage, 1996; Rosenthal, 1993; Settlage, 2000).

Central to this study is the examination of preservice elementary school teachers' understandings of the learning cycle using a newly developed and validated, national instrument, the Learning Cycle Test (Odom \& Settlage, 1996). The primary question guiding our research is: what are our preservice elementary school teachers' understandings of the learning cycle and its inherent theoretical underpinnings?

\section{Learning Cycle Test}

The Learning Cycle Test (LCT) is a 13 question, multiple-choice, two-tiered instrument designed to reveal teachers' understandings of the three-phase learning cycle (Exploration, Concept Introduction, and Concept Application). The LCT was based on propositional knowledge statements from existing research and multiple choice items derived from free response reasons given by elementary education majors, resulting in two-tiered multiple-choice items. The first tier questions pertain to the purposes unique to each phase of the learning cycle and teacher/student behaviors distinct to each phase. These questions originated from the propositional statements. The second tier provides two to four possible reasons, or rationales, that "defend" the response to the first tier question. For each test item to be considered correct, both first and second tier responses for each item must be correct. Instrument reliability of the LCT has been measured at 0.76 and the complete Learning Cycle Test can be found in Odom and Settlage (1996). Table 1 contains a representative item from each of the three phases of the learning cycle. 
Table 1. Representative Items From the LCT for Each Phase of the Learning Cycle

\begin{tabular}{|c|c|c|}
\hline $\begin{array}{l}\text { Phase } \\
\text { (Item Number) }\end{array}$ & Tier & $\begin{array}{l}\text { Propositional Knowledge Statements and } \\
\text { Answers (1st Tier) and Educational Reasons (2nd Tier) }\end{array}$ \\
\hline $\begin{array}{l}\text { loration } \\
(6)\end{array}$ & 1 & $\begin{array}{l}\text { During the first phase of the learning cycle, the teacher should give } \\
\text { directions and explain the concept that the students are investigating. } \\
\text { A. This is a TRUE statement. } \\
\text { B. This is a FALSE statement. } \\
\text { The educational reason for my answer is because: } \\
\text { A. students should be told why and what they are investigating so they } \\
\text { understand their reason for the activity. } \\
\text { B. the lesson will not have focus unless the teacher explains the concept } \\
\text { they are investigating. } \\
\text { C. the concept should be derived from the activity because telling is not } \\
\text { as powerful as the actual experience. } \\
\text { D. the teacher should not introduce the students to the concept but you } \\
\text { can tell them the results they should expect. }\end{array}$ \\
\hline $\begin{array}{l}\text { Concept } \\
\text { Introduction } \\
\quad(9)\end{array}$ & 1 & $\begin{array}{l}\text { During the second phase of the learning cycle, the teacher helps with } \\
\text { which of the following? } \\
\text { A. Additional phenomena are discussed and explored. } \\
\text { B. Students investigate phenomena first hand. } \\
\text { C. Students report their data to the class and analyze it. } \\
\text { The educational reason for my answer is because: } \\
\text { A. students verbalize what they experience under the guidance of the } \\
\text { teacher. } \\
\text { B. the teacher will interpret the data for the students. } \\
\text { C. the teacher lets the students work individually to construct meaning } \\
\text { about the concept. } \\
\text { D. hands-on activities are essential for those students who have a } \\
\text { concrete learning style. }\end{array}$ \\
\hline $\begin{array}{l}\text { Concept } \\
\text { Application } \\
\quad(10)\end{array}$ & 1 & $\begin{array}{l}\text { During the third phase of the learning cycle: } \\
\text { A. new concepts are discussed and/or explained. } \\
\text { B. additional phenomena are discussed and/or explored that involve } \\
\text { the same concept. } \\
\text { C. data are reported to the class and terms are introduced. }\end{array}$ \\
\hline & 2 & $\begin{array}{l}\text { The educational reason for my answer is because: } \\
\text { A. new concepts are assimilated during the new activity. } \\
\text { B. slightly different types of activities are used to investigate various } \\
\text { concepts. } \\
\text { C. students continue to use the concept under different circumstances. } \\
\text { D. the discussion of data is needed to support the presentation of } \\
\text { additional vocabulary. }\end{array}$ \\
\hline
\end{tabular}




\section{Theory Based Courses}

For our study,we examined preservice teachers' understandings of the learning cycle and its theoretical foundation following the completion of two courses of "elementary school science methods." During the first course, students examined Piaget's model of intelligence and the resulting inquiry teaching approach known as the learning cycle. Throughout the course, students developed understandings of the relationships between (a) cognitive and social constructivist theory and (b) the learning cycle.

The course itself modeled the three phases of the learning cycle. The main concept of this learning cycle lesson (the course) is named theory based science education. In the exploration part of the course, students engaged in several learning cycle lessons or "inquiry science lessons," targeting specific science concepts, inquiry processes, national/state standards, and knowledge construction theory. Our students began developing the understandings that (a) science is a structured, active process of discovery, (b) the central purpose of education is to develop students' critical thinking, (c) the cognitive level of the student is a major factor in determining what and how to teach, and (d) the learning cycle is a teaching approach that results from the pragmatic translation of a, b, and c (Marek \& Cavallo, 1997). Experiencing these four theory base elements is prerequisite for the concept introduction phase of the course. During concept introduction, preservice teachers constructed the theoretical basis of elementary school science education. In other words, they began to understand the relationships among learning models and how these models form the theoretical underpinnings of elementary school science education [(a) through (d) above]. Finally, in the concept application portion of the course, preservice teachers applied the concept named theory based science education by developing and teaching original learning cycles to peers. Preservice teachers in the first methods course were allowed approximately fifty minutes to teach their learning cycle science lesson to their peers as they would teach their lesson to elementary school students. If time did not allow for a full exploration, concept introduction, or concept application during the peer teaching experience, preservice teachers were encouraged to discuss the experiences that should take place during the phase or phases of the learning cycle that were curtailed.

The second or subsequent science methods course was the vehicle for these preservice teachers to again practice and apply theory based, elementary school science education. In other words, they continued to participate in learning cycle lessons focusing on selected science concepts, and they continued to develop and peer-teach original learning cycle lessons. The culminating experience of the two methods courses was teaching learning cycle lessons to elementary school children during a field experience component in an elementary school. Within these field experiences, preservice teachers taught at least three learning cycle science lessons during a 120-hour contact period covering a six-week duration in the local public schools. Preservice teachers were encouraged to reflect continually upon their teaching practices while in the public school setting. 


\section{Research Design and Procedures}

Students enrolled in the two elementary school science methods courses were elementary education majors ( $n=61,52$ females and 9 males) in their junior or senior years of study. Data were gathered from two instructors' classes over a one- year period. All student responses were coded to maintain anonymity. All elementary education majors were required to complete the two-course sequence with a grade of $\mathrm{C}$ or better.

Qualitative and quantitative data were collected for this project, which included multiple sources and different methods of gathering data to strengthen credibility (McMillan, 2000). Data sources included LCT scores (given to all participants at the end of the second methods course), written narrative responses to a question pertaining to students' perceptions of the LCT, and verbal comments made by students regarding the LCT. Creswell (1994) refers to the analysis of qualitative and quantitative data concurrently throughout the study as "simultaneous triangulation" (p. 182). The quantitative component (LCT scores) measured the participants' understandings of the learning cycle and its inherent theoretical underpinnings while the qualitative component was developed as a descriptive element, seeking to illustrate the unique and personal perspectives of preservice teachers in our courses regarding the LCT. Students were asked at the end of the second course to write comments or suggestions about the test items and make recommendations for improving the test. In using multiple data sources we employed detailed field notes, research teams, member checks and the triangulation of data to ensure the accuracy of our data (McMillan, 2000).

\section{Results/Data}

For data interpretation we grouped LCT items that were common to a particular phase of the learning cycle. For example, items 6, 7, 11, and 12 related to the exploration phase; items 3,5, and 9 pertained to the concept introduction phase; and items $1,2,4,8,10$, and 13 related to the concept application phase. From these phase specific questions, we calculated the percentages of students who answered correctly to the "responses" (First Tier), the "rationales" (Second Tier), and the "combinations" of response and rationale.

The students in our study demonstrated understanding of all phases of the learning cycle with greatest understanding of the exploration phase $(80.3 \%$ correct combinations) and least understanding of the concept application phase (47.3\% correct combinations). For the exploration phase, students had $82.4 \%$ correct responses, $91.4 \%$ correct rationales and $80.3 \%$ correct combinations of responses and rationales. For the concept introduction phase, students correctly responded to $76.5 \%$ of the questions and to $73.8 \%$ of the rationales resulting in approximately $64 \%$ correct combinations for this phase of the learning cycle. Understandings of the concept application phase resulted in $59.8 \%$ correct responses, $56.1 \%$ correct rationales and $47.3 \%$ correct combinations. See Figure 1. 


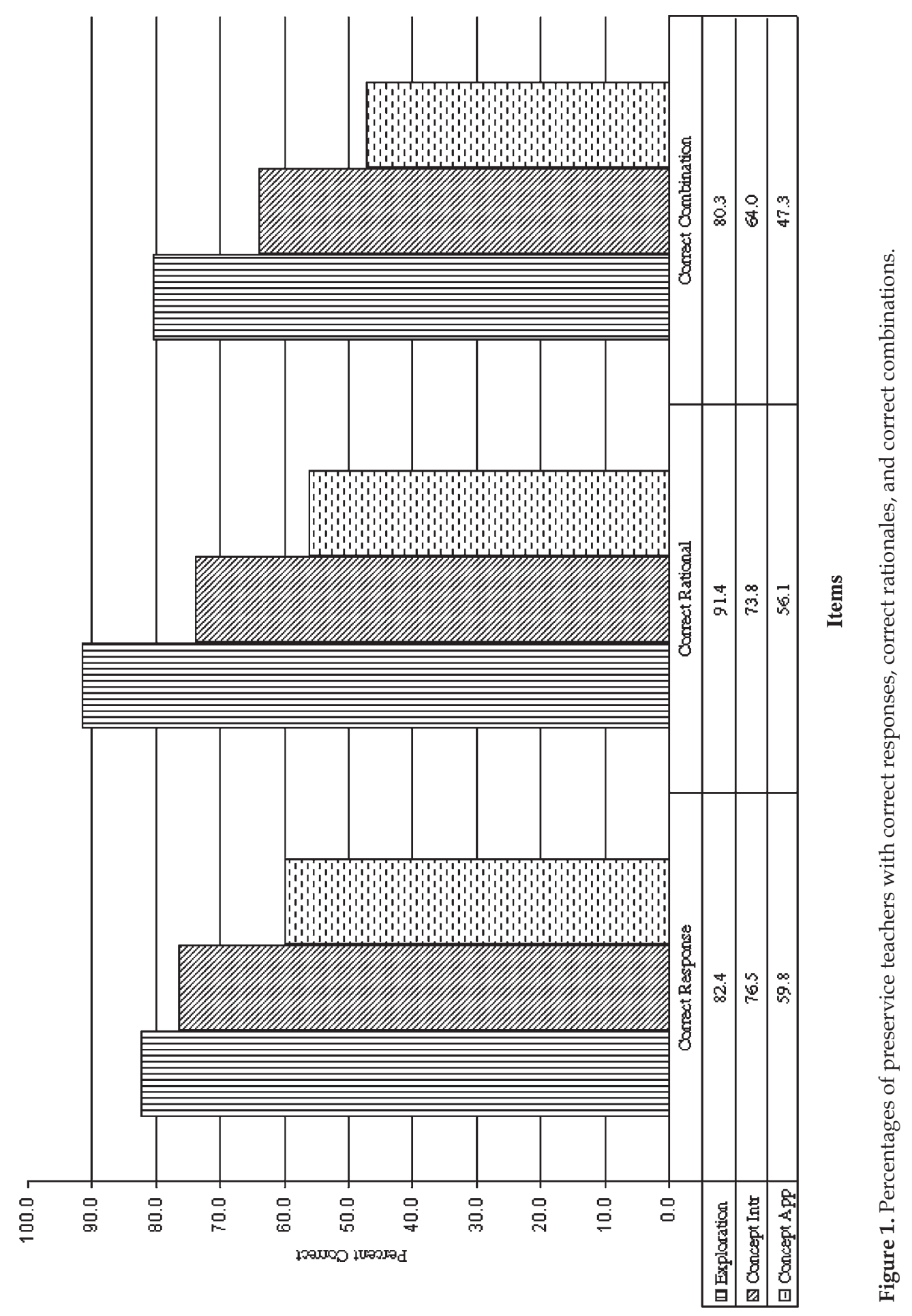


From these results several additional questions emerged in relation to the LCT and our theory based courses. Why did our students demonstrate greater understandings of the exploration and the concept introduction phases compared to the concept application phase? The concept introduction is the most complex phase to understand and teach, yet our students had lowest LCT scores on concept application questions. How did the experiences our students had in their two "methods" courses correlate to the LCT questions? In other words, did the LCT adequately measure learning cycle understandings of the students in this study? What understandings did the students in this study hold about the learning cycle that the LCT did not measure? What understandings did the students in this study hold about theory based science education that was not measured by the LCT? We will attempt to address the preceding questions in the following section. Those questions left unanswered in the interpretations/discussion section would provide the potentiality for further research.

\section{Interpretations/Discussion}

To explore possible explanations to the questions above, as well as our original research question, we followed up with a two-pronged focus. We examined (a) the qualitative data from the students provided as written feedback about the LCT and the verbal comments shared by the students, and (b) the LCT questions themselves, more specifically the rationale portions of the instrument's items.

\section{Feedback on the LCT}

Many of our students verbally expressed their frustrations while taking the LCT; these perspectives were recorded by the students on the free response portion of the LCT. For example, one student wrote, "It bothers me that I have to choose from your educational reasons on [Tier two]. Couldn't I write my own [answer]? Sometimes your answers are not mine." Another student added, "On certain questions, I felt that there was no answer that truly represented the meaning of the question. It was difficult to decipher 'the best one'." A similar response was given stating, "Letter ' $C$ ' is better than 'A, B, or D' for my first answer but still isn't the definitive conclusion for my educational reason."

In many places on the LCT, the educational reason (rationale) did not coincide with our students' beliefs. In other words, the LCT choices did not offer an option that represented our students' understandings of theory based science education. For example, one student stated, "The educational reasoning for answers often does not match the reasoning that we have been taught. I think some of the reasoning for the 3rd phase was confusing and made me question if I understand it from what we learned in class." One of our students was frustrated with the method of assessment (LCT) and its inconsistency with the learning cycle philosophy. This student commented, "What a bad way to evaluate the learning cycle. I thought the learning cycle was more open-ended than your test questions allowed...". The students in this study knew more about the theoretical underpinnings of the learning cycle that the LCT measured. 
Given the LCT was the only validated assessment instrument that measured teachers' understandings of the learning cycle at the time of our study, we were motivated to determine the compatibility of using this test instrument in our methods courses. We attribute the related frustration of our preservice teachers to the twotier design of the LCT format, which forced some preservice teachers to select an educational reason (rationale) that possibly did not correspond with their own beliefs and understandings. Thus, these preservice teachers presumed the LCT did not provide suitable responses that allowed for their own selective freedom of choice. We will address these perceived incompatibilities with the LCT in the conclusions section.

\section{LCT Items}

As we expanded toward the larger set of questions that emerged from this study (and possible explanations to those questions), we further analyzed the LCT by examining each item. Examination of LCT items was guided by two key questions: what did we teach our students about each phase of the learning cycle and how did we teach our students about each phase of the learning cycle? For example, item 12 is designed to measure students' understandings of the exploration phase and provided three choices [During the first phase of the learning cycle, the teacher: (a) is a major informational resource for the student, (b) facilitates the process of observing and recording data, and (c) keeps the students on-task and manages their behavior.] and four rationales [The educational reason for my answer is because: (a) students must have the important concepts defined at the same time that they are working with materials, (b) the teacher may provide the data to the students for them to analyze, (c) students should be provided with the material from which they are to gather data, and (d) students should be prevented from sharing their ideas with others prematurely.].

Although most of the students in this study (83.6\%) gave the correct rationale [C], only $42.6 \%$ gave the expected response [B]. Our preservice teachers' answers were shared between two responses [B and C] because they were taught that the teacher's role during the exploration is to facilitate the process of gathering data [B] and to keep students on task [C]. One student said, “On \#12, I didn't think the reason really applied to the first part. Also, on the first part, a teacher facilitates the exploration, but he/she must also keep the students on task, and behaving." And another student succinctly stated, "\#12 [B-C] could also be C-C."

Results from several other items on the LCT can be attributed to similar mismatches between what we taught about the learning cycle and what the LCT measured. Note the bar graphs in Figure 2 for items 4, 8, and 13. These three items pertained to the concept application phase of the learning cycle and most students in this study gave "wrong" answers. 


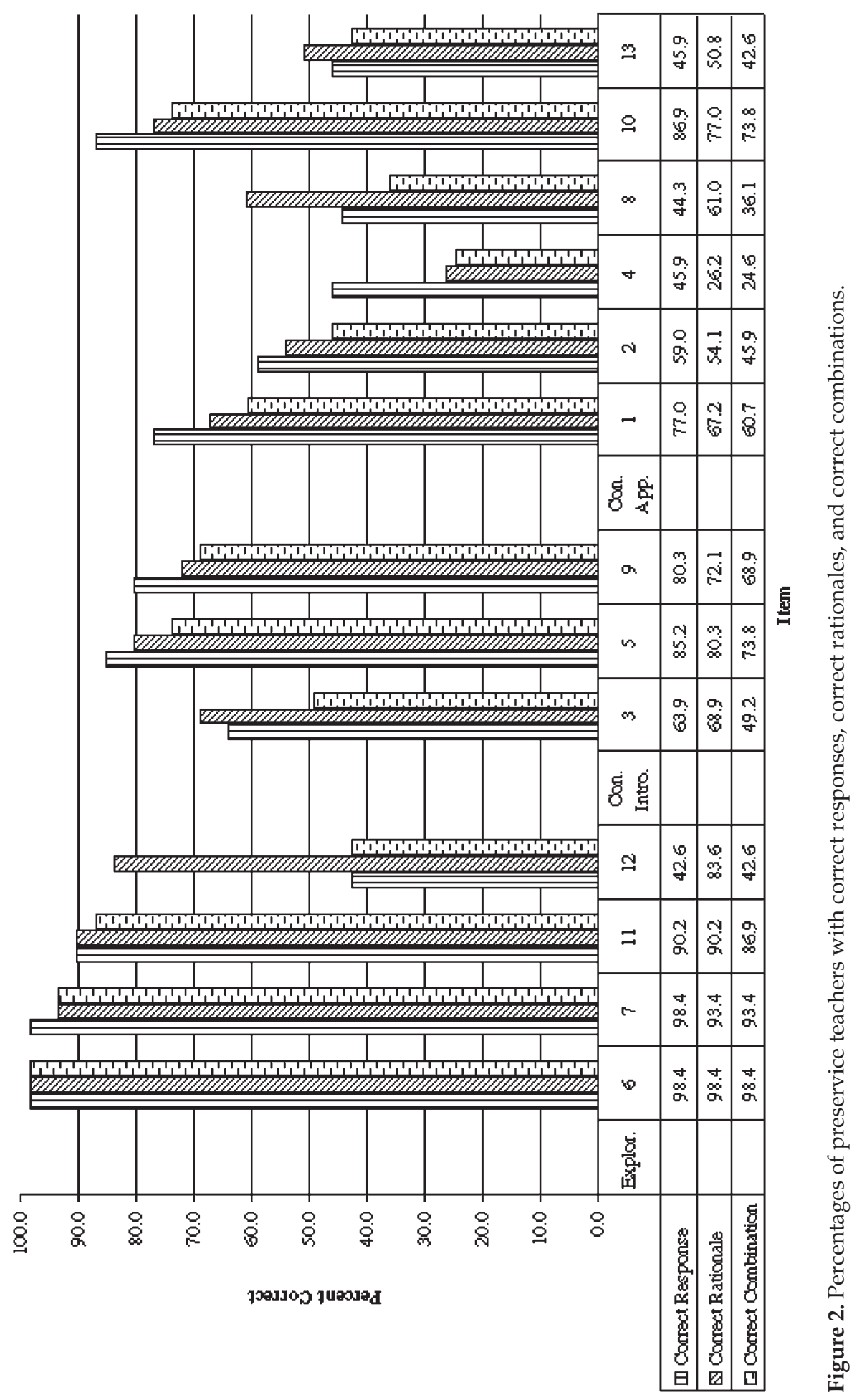


When we examined the qualitative data (see the comments above), we discovered that their comments were more closely aligned to the established theoretical underpinnings of the learning cycle than to "correct" answers on the LCT. For example, a student wrote:

Throughout this test, I remained consistent in answering questions about the third phase. I said that the purpose was to extend the concept with a different activity/different context. However, it could be appropriate to make connections between other concepts and build on their knowledge by extending matter to weight for example. My question: is this part of phase 3 or a new learning cycle?

Of course the answer to this student's question is, "it depends on the concept, or perhaps on the particular learning cycle, or sometimes, it depends on the instructor." The main thing to remember is that the central purpose of the concept application phase of the learning cycle is to allow students to relate their newly learned concept with their prior knowledge.

\section{Conclusions}

Odom and Settlage (1996) indicate that the learning cycle teaching approach is a difficult, complex and abstract structure to understand. We do not disagree. Unmistakably the results showed that our students demonstrated differing degrees of understandings of each phase of the learning cycle after completing the two methods courses. However, as we further analyzed the data, all indications are that there is a probable mismatch between the LCT and the concepts learned in the two courses. This mismatch is clearly reflected through the comments made by students regarding the LCT, their written critiques, and the rationales used (Tier 2 responses) on the LCT. Additionally, to further enhance the validity and reliability of the LCT for use in our program, we propose identifying those responses and/or rationales that are not consistent with our theory base and replacing or modifying incongruous test items.

The LCT proved to be a useful tool for measuring some aspects of our preservice teachers' understandings or misunderstandings of the learning cycle. For example, we learned that our students likely knew least about the concept application phase of the learning cycle. Perhaps others would make similar discoveries using the LCT. But again, we found considerable mismatches between the LCT and the concepts (the theory base for elementary school science) learned in the methods courses. Our methods courses are designed to develop understandings of theory based, elementary school science education within which the learning cycle is a central component. A key element of these courses is the opportunity to implement learning cycle science lessons in field experiences that our preservice teachers complete. Our students, preservice teachers, have the opportunities to reflect upon their experiences of developing and teaching learning cycle lessons to students in elementary school classrooms. Our expectations are that these reflective processes lead to an increased understanding of the learning cycle and its theoretical underpinnings (Francis, Tyson, \& Wilder, 1999; Hamilton \& Hitz, 1996; Wedman, Espinosa, \& Laffey, 1999). Since we found that our students' comments 
were more closely related to the theoretical underpinnings of the learning cycle rather than the answers and rationales on the LCT, we recommend that others closely examine the theory base and the expectations of their course(s) and determine if they match, or are measured by, the LCT.

As we stated previously, underpinning our science education program is a theoretical foundation; and four questions define the parameters of that theory base for elementary school science education:

\section{What is science?}

2. What are the goals or standards for elementary school science education?

3. What theory describes how elementary school children construct knowledge?

4. What teaching approach represents the discipline of science, achieves the goals of elementary school science education and accommodates to how children construct knowledge?

By reviewing and making modifications, the LCT could be a convenient vehicle to measure parts of some of these questions. In our own program, we intend to make modifications to the LCT so that it may be a better vehicle to measure parts of our theory based science education program. In particular, we intend to add "blank" spaces to the LCT so that preservice teachers can create and write their own reasons beyond those listed in the LCT rationales. We see this change as something that will improve the LCT for our methods courses and provide better data on which to make decisions regarding these courses.

\section{References}

American Association for the Advancement of Science. (1990). Science for all Americans: Project 2061. New York: Oxford.

American Association for the Advancement of Science. (1993). Benchmarks for science literacy. New York: Oxford.

American Psychological Association. (1998). How students learn: Reforming schools through learner-centered education. Washington, DC: APA.

Barman, C. R. (1992). An evaluation of the use of a technique designed to assist prospective elementary teachers use the learning cycle with science textbooks. School Science and Mathematics, 92(2), 59-63.

Barman, C. R. (1993). The learning cycle: A basic tool for teachers, too. Perspectives in Education and Deafness, 11(4), 7-11.

Barman, C. R. \& Kotar, M. (1989). Teaching teachers: The learning cycle. Science and Children, 26(7), 30-32.

Barman, C. R. \& Shedd, J. D. (1992), An inservice program designed to introduce k6 teachers to the learning cycle teaching approach. Journal of Science Teacher Education, 3(2), 58-64.

Bentley, M., Ebert, C. \& Ebert, E. S., II (2000). The natural investigator: A constructivist approach to teaching elementary and middle school science. Stamford, CT: Wadsworth Thompson. 
Blank, L. M. (2000). A metacognitive learning cycle: A better warranty for student understanding? Science Education, 84(4), 486-506.

Cavallo, A. M. L., \& Laubach, T. A. (2001). Students' science perceptions and enrollment decisions in differing learning cycle classrooms. Journal of Research in Science Teaching, 38(9), 1029-1062.

Creswell, J. W. (1994). Research design: Qualitative and quantitative approaches. Thousand Oaks, CA: Sage.

Creswell, J. W. (1997, March). Composing a mixed-method study. Paper presented at the annual meeting of the American Educational Research Association, Chicago, IL.

Dwyer, W. M., \& Lopez, V. E. (2001, June). Simulations in the learning cycle: A case study involving "Exploring the Nardoo." Paper presented at the meeting of the National Educational Computing Conference, Chicago, IL.

Francis, A., Tyson, L., \& Wilder, M. S. (1999). An analysis of the efficacy of a reflective thinking instructional module on the reflective thinking demonstrated in the field experience logs of early elementary preservice teachers. Action in Teacher Education, 21(3), 38-44.

Francis, R. G., Hill, D. M., \& Redden, M. G. (1991). Mathematics and science: A shared learning cycle and a common learning environment. School Science and Mathematics, 91(8), 339-343.

Gang, S. (1995). Removing preconceptions with a learning cycle. Physics Teacher, 33(6), 346-354.

Glasson, G. E., \& Lalik, R. V. (1993). Reinterpreting the learning cycle from a social constructivist perspective:A qualitative study of teacher's beliefs and practices. Journal of Research in Science Teaching, 30(2), 187-207.

Hamilton, D., \& Hitz, R. (1996). Reflections on a constructivist approach to teaching. Journal of Early Childhood Teacher Education, 17(1), 15-25.

Jinkins, D. (2001). Impact of the implementation of the teaching/learning cycle on teacher decision-making and emergent readers. Reading Psychology, 22(4), 267-288.

Joyce, B., Weil, M., \& Calhoun, E. (2000). Models of teaching (6th ed.). Needham Heights, MA: Allyn and Bacon.

Lavoie, D. R. (1999). Effects of emphasizing hypothetico-predictive reasoning within the science learning cycle on high school student's process skills and conceptual understandings in biology. Journal of Research in Science Teaching, 36(10), 1127-1147.

Lawson, A. E., Abraham, M. R., \& Renner, J. W. (1989). A theory of instruction: Using the learning cycle to teach science concepts and thinking skills. NARST Monograph, Number One, National Association of Research in Science Teaching.

Marek, E. A., \& Cavallo, A. M. L. (1997). The learning cycle: Elementary school science and beyond (Rev. ed.). Portsmouth, NH: Heinemann.

Marek, E. A., Eubanks, C., \& Gallaher, T. H. (1990). Teachers' understanding and the use of the learning cycle. Journal of Research in Science Teaching, 27(9), 821-834.

Marek, E. A., \& Methven, S. B. (1991). Effects of the learning cycle upon student and classroom teacher performance. Journal of Research in Science Teaching, 28(1), 41-53.

McMillan, J. H. (2000). Educational research: Fundamentals for the consumer. New York: Longman.

Musheno, B. V., \& Lawson, A. E. (1999). Effects of learning cycle and traditional text on comprehension of science concepts by students at differing reasoning levels. Journal of Research in Science Teaching, 36(1), 23-37. 
National Research Council. (1996). National science education standards. Washington, DC: NRC.

National Research Council. (1999). How people learn: Brain, mind, experience, and school. Washington, DC: NRC.

National Science Teachers Association. (1998). NSTA/NCATE standards for science teacher preparation; on-line at: http:// homepages.ius.edu/LZ/SGILBE01/web_docs/nsta98.htm

Norman, J. T. (1992). Systematic modeling versus the learning cycle: Comparative effects of integrated science process skill achievement. Journal of Research in Science Teaching, 29(7), 715-727.

Norman, K., \& Caseau, D. (1995). The learning cycle: Teaching to the strengths of students with learning disabilities in science classrooms. Journal of Science for Persons with Disabilities, 3(1), 18-25.

Odom, A. L., \& Kelly, P. V. (2001). Integrating concept mapping and the learning cycle to teach diffusion and osmosis concepts to high school biology students. Science Education, 85(6), 615-635.

Odom, A. L., \& Settlage, J., Jr. (1996). Teachers' understanding of the learning cycle as assessed with a two tier-test. Journal of Science Teacher Education, 7(2), 123-142.

Renner, J. W., \& Marek, E. A. (1990). An educational theory base for science teaching. Journal of Research in Science Teaching, 27(3), 241-246.

Rosenthal, D. B. (1993). A learning cycle approach to dealing with pseudoscience beliefs of prospective elementary teachers. Journal of Science Teacher Education, 4(2), 33-36.

Settlage, J. (2000). Understanding the learning cycle: Influences on abilities to embrace the approach by preservice elementary school teachers. Science Education, 84(1), 43-50.

Spradley, J.P. (1980). Participant observation. NewYork: Holt, Rinehart \& Winston.

Wedman, J. M., Espinosa, L. M., \& Laffey,J. M. (1999). A process for understanding how a fieldbased course influences teachers' beliefs and practices. Teacher Educator, 34(3), 189-214. 